\title{
The facilitation of the formation process of the conceptual foundation of students
}

\author{
Rustam Shaykhutdinov ${ }^{1}$, Maria Sadritdinova ${ }^{1 *}$, and Mikhail Kochurov² \\ ${ }^{1}$ Schnittke Moscow State Institute of Music, Moscow, Russia, 10, Marshal Sokolovsky str., 123060, \\ Russia \\ ${ }^{2}$ Zagir Ismagilov Ufa State Institute of Arts, Ufa, Russia 14, Lenin Street, Ufa, Republic of \\ Bashkortostan, 450008, Russia
}

\begin{abstract}
The article presents practicing pianists and teachers' recommendations and advice on how to form the process of the conceptual foundation of students of higher education institutions. Scherzo No. 1 in B minor op. 20 F. Chopin is one of the brightest masterpieces of the romantic piano repertoire was chosen as an example. In the tradition of Russian music pedagogy, the authors encourage the young pianist to work on the Scherzo from the idea of composing it to details and nuances connected with professional aspects of the artistic conception; they want to encourage the constant striving for thoughtful, comprehensive rich content and perfect form of the performed opus. Thus, to actualize students' personal, cognitive and creative potential, the teacher facilitates the process of acquiring their unique interpretations of a given musical opus. Such a method of facilitation is in demand in Western pedagogy; it was actively developed by such scientists as C. Rogers, J. Freiberg, F. Flemming, T. Kaiser, and others. The main ideas of facilitation are reflected in the pages of their works "Freedom to Learn" [1], "Transformative Dialogues" [2], " Mining Group Gold: How to Cash in on the Collaborative Brain Power of a Team for Innovation and Results " [3] and many others. The "Methods" section presents a detailed model to analyze the musical form of the Scherzo, the problems on the content and artistic image that is based on a thorough study of the musical text and its sound embodiment through.
\end{abstract}

\section{Introduction}

Music students of performance specialties are always faced with the special relevance of creating an exciting, persuasive, memorable interpretation of pieces of music. Since students of higher educational institutions have already accumulated sufficient emotional and

* Corresponding author: mariiasadritdinovane@yandex.ru 
aesthetic experience, achieved a significant degree of professional freedom, reinforced the musical skills, mastered a large repertoire, and gained an understanding of the specifics of artistic styles and genres, they begin to feel the need to express their performance positions in certain opus. The teacher deliberately abandons dogmatic authoritarian principles and strategies; he/she assumes the noble function of facilitator, he/ she outlines the milestones and reference points on the way to develop a conceptual foundation, helps the student to find his/her bearings in the semantic field of aesthetic values and philosophical categories, corrects the "purity" of artistic taste, initiates analytical work and encourages and stimulates the student creative activity.

According to leading experts at the Russian State Social University, the main task of a modern teacher, mentor, and master - facilitator "is to contribute to the formation of various aspects of the personality, his/her self-consciousness, spirituality, and culture, initiative, independence, tolerance, the ability to successful socialization in society and active adaptation to the labor market" $[4,16]$.

In the context of musical performance, the teacher can make recommendations regarding the construction of the general "drama" of the piece of music, its ideological and imaginative plan, and the semantic content of individual episodes. In addition, the teacher facilitator's prerogative is to make suggestions on how to strengthen the mode key, stroke technique, and figurative contrasts, how to reveal less obvious intonations, how to outline melodic contours, how to implement the genesis of sound symbols, and, finally, how to reach the level of the deepest artistic and philosophical generalizations.

Similar work was carried out with several pianists and master's students of "Musical and instrumental art" Moscow State Institute of Music named after A.G. Schnittke, who have purposefully chosen F. Chopin`s Scherzo No. 1.

The performers (both acclaimed piano masters and students) will gain an incredibly rich room to display their attitude towards F. Chopin's Scherzo No. 1 score and reveal their interpretations: the opus combines classically refined form and vividly romantic content; it has a deep, truly Chopin-like soulfulness and a "super-Chopin-like", almost Liszt-like intensity of dramatic passion. "His piano compositions are well known for their poetic and musical structures, cantabile melodies and tones, ingeniously harmonious language, and profound national emotions" $[5,263]$ is the authoritative opinion of scholar Mingchun Li about Chopin's compositional style.

The task of the performer is to see the textual details, comprehend them, and piece together a coherent, meaning-filled concept of a romantic masterpiece, while the task of the facilitator is to optimize and adjust this process.

\section{Methodology}

It is a long, complex process to create a conceptual foundation, and it can be presented as a universal integrated model.

2.1 The first stage is to study the prerequisites for the creation of a piece of music, the consideration of the personal author's "motives" and the "fit" of the work in a certain historical context - "reflecting the surrounding and the inner world in artistic images" $[6,55]$.

Thus, the events of the Polish uprising of 1830-31 were an emotive subject to F. Chopin; they could not help but find expression in his music.

The images of Scherzo No. 1 are vivid, the characteristics are extremely definite, and the pain is piercing... Thus, it is possible to observe that the genre code "The Man and the People Historical Tragedy» forms the basis of the ideological sphere of Scherzo No. 1 [7, 205].

The first Scherzo chords are quite unusual for F. Chopin, who used to begin an extended piece of music with an unhurried entrance, a kind of "intro" (a balladic, narrative technique). However, according to the observation of N.B. Bondarenko, a researcher of Chopin's oeuvre, 
there is nothing unusual, and "the polemic of forms should be considered as a symptomatic phenomenon for the musical thinking of the Polish composer" [8, 76].

Scherzo No. 1 "Chords of Horror" are verging onto the beginning of Beethoven's Ninth Symphony conclusion. They immediately give us a sense of the peak-to-peak value, the mood for something special and exceptional.

The complex formation process of the conceptual foundation

The first stage - the study of the prerequisites for the creation of a piece of music, the consideration of the personal author`s «motives" and the "fit" of the work in a certain historical context

The second stage is a detailed and careful analysis of the score (study, comparison, evaluation, modeling, classification and generalization of the extracted information).

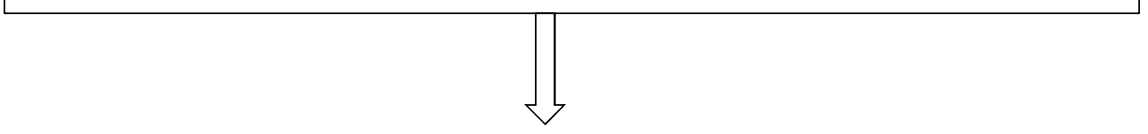

The third stage is the identification of individual attitudes toward the piece of music and the final formulation of one's own performance concept.

Fig.1. The universal integrated model of creating a conceptual foundation.

The beginning of the presentation of the main material is striking in its intensity, the indomitable energy of the coloration that soars up towards the accented climaxes. Numerous remarks $\longrightarrow$, cresc. and sf - with an overall initial level of piano dynamics - create a sense of thunderous night flashes.

2.2 The second stage is a detailed and careful analysis of the score.

The opinion of the researcher of musical semantics V.E. Devutsky about the gradual disclosure of a music piece emotional palette by discovering the meanings and values behind the individual "details" of the musical texture is valuable: "Thus, the transmission of emotional information in music appears to be a very complex semantic system, it requires musicians and listeners to accumulate their many years of musical experience" $[9,16]$.

At this stage the student demonstrates and develops his/her ability to study, compare, evaluate, model, classify and summarize retrieved information. As Ted Thomas, an educatorresearcher whose area of scholarly interest is to study the development of freshmen critical thinking, notes: "Students need to learn to find, evaluate, and use high-quality evidence to back up their arguments" [10,29]. Thus, a solid "knowledge" base for the future conceptual foundation will be laid.

It is most appropriate to begin the analysis by recognizing the form of the piece of music. Let us outline the Scherzo scheme. The turbulent, tragic piece of music, with its peaks and 
abysses, tense growth, and contrasts, turns out to be a complex three-part form, traditional for classical Scherzos.

The beginning of the main material is forceful, with irrepressible energy. The next section contrasts with the previous one. The tempo slows down, the restrained dynamics in the middle and lower registers prevail, and the two lines engage in an agonizing dialogue, exchange mournful, groaning intonations. This fragment clearly expresses a personal, individual beginning, whereas the rapidly swirling lines of the previous section are perceived as something generalized.

The performer must pay special attention to hearing and embodiment of melodious, intonable chords and octaves, to indicate the increasing priority of the upper voice, to choose the most legato touch notation.

Another performance difficulty is the repetition in the author's text. From a formal point of view, the Scherzo has no through-composed unraveling of the plot: the unchanging musical material is repeated over and over again. The performer must seek the harmonious balance between these repetitive episodes based on a scrupulous analysis of the score and the differences. The conclusion is a great opportunity for the pianist to demonstrate his/her artistic impression and subtle improvisational sense.

The crossfade to the trio is gentle as if it is a dream. The first sixteen bars sound like a berceuse: framed by the even, soporific rocking of the quavers and the measured tonic basses, the theme of a Polish Christmas song emerges in the warm alto register, like a lucid dream.

The details of the author's recording, the indication sotto voce e ben legato show the sound atmosphere reigns here, intimate and rather fragile. The exaggerated emphasis on certain sounds of the melody in several versions (e.g. by K. Klindworth) leads to excessive affectation, it seems unconvincing (we also recall examples of some interpretations, such as the early recording by $\mathrm{V}$. Horowitz and others):

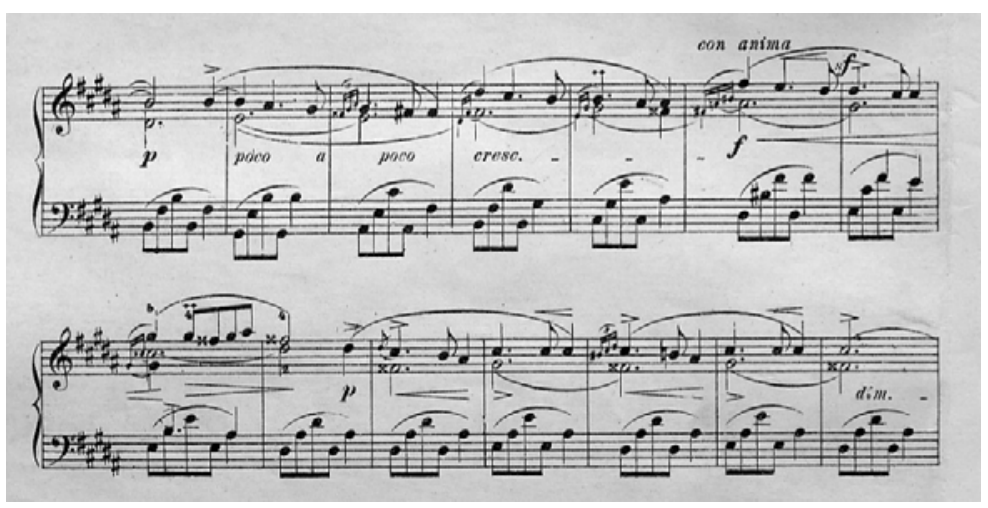

Fig. 2. Music score 1.

F. Chopin. Scherzo No. 1 / ed. K. Klindworth

Notably, F. Chopin, who chose the traditional three-part form for his Scherzo, did not (apart from the first section A) place his trust in the usually applied graphic signs of the reprise, and consequently ruled out the possibility of different interpretations of the conventional musical notation: all repetitions in the trio, just as in the outer movements, are written out in full; in this case, they contain the very slightest textual changes which are of particular interest for the performer and make the music evolve and alive.

The general performance scheme of the trio appears to be mirror-like to the first part ${ }{ }^{C} C_{2}$. It is possible to play the middle working out of the carol un poco piu espressivo, to start a more intense voice production with the supporting voice stroke of g-fis-e-dis (t. 335- 
337). The consequence will be high excitement; the textual differences in the section from its first performance indicate it.

The more natural and organic is the final section of the trio: pianissimo; sempre dim. e rall.; ritenuto; smorzando. Note that the sharp intruding ff chords, which decisively and unambiguously interrupt the material of the middle section, are not of the same duration; accordingly, they should be given a different meaning and sound:

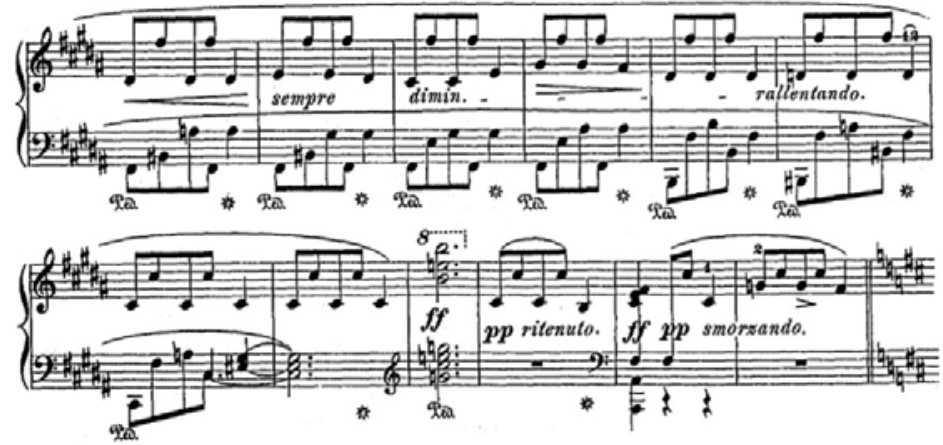

Fig.3. Music score 2.

F. Chopin. Scherzo No. 1

A particular difficulty for the performer is the instantaneous switch from a state of gentle " thawing" to the violent excitement of the reprise, which begins at the same level of tension in the climax of the first movement (molto con fuoco).

The fragment preceding the coda is the highest point of dramatic tension, which is expressed in a fuller sound, in intonation and rhythmic aggravation, and the declamatory whoops of the upper voice.

A semantic arc is thrown from the ending that precedes the trio to the analyzed bars: the E-sharp, which softened before the trio and turned into E-becar, finally breaks through to the F-sharp and then to the dominant ninth chord, which marks the dramaturgical denouement.

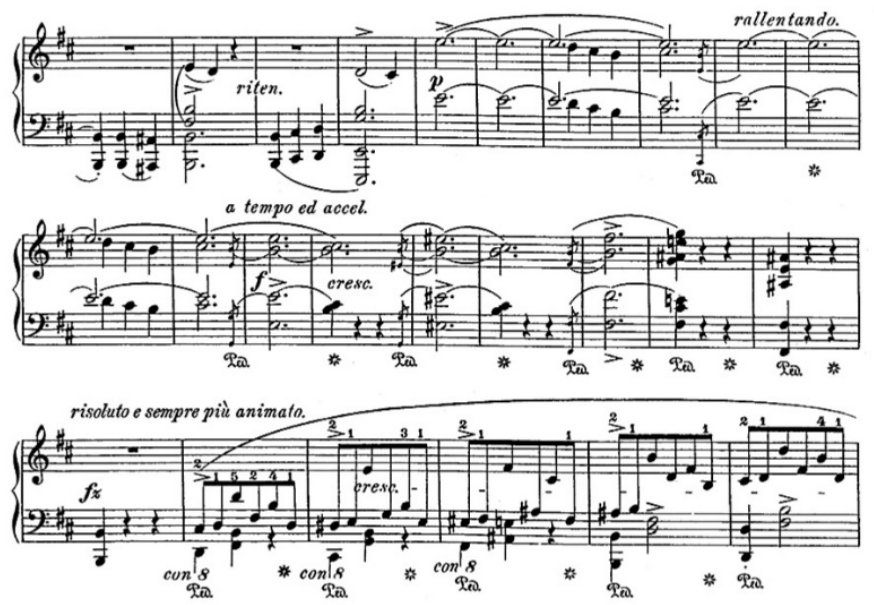

Fig. 4. Music score 3. F. Chopin. Scherzo No. 1.

The coda is a whirlwind of confused emotion, expressed by techniques of Liszt's peakto-peak value and impressive power. At the same time, Chopin retains his maximally detailed 
recording, which manifests itself, among other things, fundamental differences in the lefthand part; it should be revealed by the change in pedaling.

2.3 The third stage "The identification of individual attitudes toward the piece of music and the final formulation of one's performance concept" begins when the detailed study of the music score has been completed and all of the composer's instructions have been taken into account. According to the famous teacher and practicing pianist Ruoxu Chen, it is at this stage that "an opportunity opens up to wholly free the performers from the written page and to truly own the piece" $[11,112]$.

The position of the researcher of the structure of musical thinking V.P. Sradzhev seems convincing: "Specially organized, music and aural representations, which are formed into musical and aural images, are determined by emotional and intellectual factors ... give the image sphere an individual shade, that reflects the specific properties of each person's thinking" $[12,87]$.

At this stage, the fullest students 'fulfillment, self-actualization mechanisms are triggered, the experience of personal experiences and associative relationships is actualized, the knowledge of sidelines of science: philosophy, aesthetics, musicology, poetry, painting, etc. is acquired.

\section{Results}

The work on the formation of a value the conceptual foundation of F. Chopin's Scherzo No. 1 , as well as of other music pieces, based on the proposed methodological plan, certainly contributes both to a more intensive skills development in understanding and implementing the author's idea, and to the ability to implement their creative ideas and solutions most clearly and cconvincingly. This was confirmed by students successful performances in concerts and examinations by using this method. Each performer received high praise and approval from the audience. "Music is considered as a source of knowledge, that drawer emotional and intellectual "charge" of it for the comprehensive development of the individual's creative potential" $[13,100]$. This process enriches the spiritual world of students, expands their professional horizons, and takes them beyond the basics of theoretical knowledge. And with the help of the guiding function of the teacher, who provides the most optimized functioning of his/her students, effective results are achieved even more rapidly, and thus, a musician-performer gains not only a productive system of professional but also multicultural skill sets. Of particular note is a facilitative approach, and a special way of communication in the system "teacher-student", "students valued feedback and were aware of its importance to achieving learning outcomes" [14, 78].

The opinion of scientists of the Khabarovsk State Institute of Culture also expresses a common position that the aim of art education is "not only to train professional personnel for the cultural sector but also to disseminate knowledge about the spiritual heritage of mankind, the development of creative potential and formation of an integral personality, its intellectual and emotional richness" [15, 147]. The more successful these goals are realized, the more interesting and meaningful will be the personal and professional identity of each musical institution graduate, and the more vivid and exciting will be their performing concepts.

\section{Discussion}

To consider the problem of analytical comprehension of the music score by the studentperformer, it is impossible not to mention the name of a specialist of musical semantics I.V. Alekseeva. She notes that the meaning of the music score "will never be exhausted ... and without the musician's awareness of the specific content of the music score, it is impossible 
to develop a personal attitude to the author's intention, that provides accuracy, brightness, and originality of interpretation of the performed piece of music" $[16,177]$. The textual analysis of F. Chopin's Scherzo No. 1. according to the above methodological scheme confirms this position.

Changqui Wang, an expert in creative psychology tells about the importance of the intensive thinking activity of students who are eager to create their conceptual foundation: "Inspiration thinking of pianists lies under their deep thought, and is a product of mutual interaction between consciousness and subconsciousness, closely connected with living experiences, musical environment, and psychological environment of a subject. Piano music, literature poetry, internal rhythm, external rhythm, Nature, environment, and impression are significant induction factors to lead inspiration thinking of pianists, while arduous practice, gifted perception, tough exploration, and smart capture are preconditions of inspiration happening in pianists. [17, 44].

As a rule, a music score gives exhaustive information about the form, the rhythmic organization of the musical material, phrasing, stroke technique nuances, dynamic tones, pedaling, fingering principles, and so on. And an attentive, cogitative student can catch a lot behind the conventional notation of the musical score, to interpret the author's remarks and editing in general as accurately as possible. However, as for the further search for interesting deep connotations, impressive images, colors, ideas - everything that leads the student to a bright, memorable, unique interpretation of a piece of music - it is not so clearly imprinted on the pages of the music score and it requires a student's intense inner work and the teacher's support. The noble mission of the teacher-facilitator is to help the student to "stage" the plot plan, to reveal the rich palette of sound colors, to expand the figurative and semantic room, and, finally, to provide an example of philosophical music understanding.

A leading specialist of music pedagogy A.I. Scherbakova has an entire concept of the oeuvre axiology, according to which "in the music score, meanings and values of the person are hidden, if using a specific language of music the image of the world, requiring a philosophical understanding of it, is heard to the listener, so such a text can be considered as" [18, 99]. Doctor of Pedagogical Sciences I.A. Korsakova holds a similar position, emphasizing that "the ability to see, understand and create the Beauty is the basis of deep comprehension of life through art" [19,569].

One cannot but agree with the well-known scientists of the Mordovian Pedagogical Institute I. S. Kobozeva, M. P. Mironova, and N. I. Chinyakov that such components of successfully presented interpretation of a piece of music as "notional value", "content and meaning", "depth of meaning and emotional richness", "idea", "originality" [20, 40] become a priority.

The student-performer must solve for him/herself the issues of sensemaking and genesis of the key image symbols while analyzing the music score and, later, postulating his/her interpretation of the piece of music to the public. Otherwise, it will be impossible to reveal the composer's intention and present a coherent, meaningful, highly spiritual concept of a masterpiece of musical art. The opinion of the researchers of the spirituality phenomenon in the aspect of P.S. Volkova and V.I. Shakhovsky`s artistic creativity is that "nonsense acts as a marker of spirituality, but sensemaking correlates with the spirit" [21, 187] is in solidarity with this.

\section{Conclusions}

In summary, it is very important to have the teacher facilitator's support, to acquire a decent, individualized, highly artistic performance concept, to facilitate the understanding of the expansion of logic of the image-symbolic sphere, to study self-regulation, self-expression, and self-creation mechanisms, to unlock the textual potential of a particular piece of music. 
These are extremely important components of successful interpretation. After all, the researcher of the Laboratory of Musical Semantics I. V. Alexeeva notes "the text needs an assessment of its didactic potential, as well as the performer's special techniques research and the ways of creative interaction ". [22, 177].

Besides, nowadays the necessity to build and present an interesting memorable interpretation of a piece of music is caused by the increasing requirements to the quality of professional training musicians, to the level of their general literacy and awareness in the field of allied sciences; it is also caused by the students desire to achieve the maximal result of their educational activity and their further interest to be competitive in the labor market. Besides, we should not forget that after graduating from the higher education institution, the student will have to implement his/her creative solutions, to determine the trajectory of his/her creative path. Therefore, as long as there is an opportunity for "polyphonic" cooperation with an experienced and understanding mentor, the student should aim "not just to develop an understanding of beauty, but the practical ability to express oneself understanding and sense of beauty, own attitude to translate into artistic forms" [23, 102]. And this will be the key to the adequate realization of the author's idea, the actualization of one's own personal, creative, intellectual potential, and, of course, the creation of a unique convincing performance concept.

\section{References}

1. C. Rogers, J. Freiberg. Freedom to Learn (M.: Smysl, 2002)

2. F. Flemming. Transformational Dialogues. An instruction manual of practical techniques for facilitating personal change (Translation from English -Kyiv: D.A. Ivakhnenko, 1997)

3. T. Kayser. Mining Group Gold: How to Cash in on the Collaborative Brain Power of a Team for Innovation and Results (M.:Mann, Ivanov and Ferber, 2017)

4. N. Anufrieva, E. Anufriev, I. Korsakova, I. Slutskaya, A. Sherbakova, Formation of Modern Musician's Personality in Educational Environment of Higher Education Institution: Complex Approach, 13-18 (2017), doi:10.5539/ass.v11n6p13

5. M. Li, On Piano Teaching with the Aid of Classical Chinese Poems: A Case Study on Chopin's Etude OP 10, 3, 263-270 (2017), doi:10.5539/ass.v10n19p263

6. L. M. Sedunova, Monitoring the quality of music education in schools of Russia, 54-63 (2017), DOI: 10.18413/2313-8971-2017-3-4-54-63

7. O. V. Begicheva, P. L. Kazantseva, The National-Historical Ballad in the Musical Art of Romanticism: Towards Posing the Problem, 205-215 (2019), DOI: 10.17674/19970854.2019.4.205-215

8. N. B. Bondarenko, On the Genre-Related Dramaturgy of Frideric Chopin's Nocturne in G Minor, OPUS 15, 76-82 (2016) DOI: 10.17674/1997-0854.2016.1.076-082

9. V. Devutskiy, Emotional Palette of Music as a Semantic System 16-28 (2018), DOI: 10.17674/1997-0854.2018.4.016-028

10. T. Thomas, Developing First Year Students' Critical Thinking Skills, 26-35 (2011), doi:10.5539/ass.v7n4p26

11. R. Chen, Memorization of Piano Music: A Challenge for Chinese Piano Students, 112118 (2016), doi:10.5539/ass.v12n3p112

12. V.P. Sradzhev, Psychological characteristic of the structure of musical thinking, 87-97 (2019), DOI: 10.18413/2313-8971-2019-5-4-0-8 
13. N.I. Anufrieva, E.A. Anufriev, I.A. Korsakova, A.I. Shcherbakova, Worldview Formation of the Teacher-musician Personality in the Higher Education System, 99104 (2015), doi:10.5539/ass.v11n6p99

14. A. D. Rowe, L/ N. Wood, Student Perceptions and Preferences for Feedback, 78-88 (2008), DOI:10.5539/ass.v4n3p78

15. E.V. Savelova, N. Ph. Semyonova, A.V. Tyurin, The Culturological Aspects of the Pedagogue Musician's Professional Training in Cultural Higher Educational Institutes of the Russian Far East, 144-156 (2020), DOI: 10.33779/2587-6341.2020.3.144-156

16. I.V. Alekseeva, The Musical Text of Western European Baroque Instrumental Music in a n Analytical Reevaluation by the Student-Performer of Institutions of Higher Education, 177-193 (2020), DOI: 10.33779/2587-6341.2020.1.177-193

17. C. Wang, Inspiration Inducement of Pianists in a Subconsciousness Background, 44-48 (2009), DOI: 10.5539 / ass.v5n6p44

18. N.I. Anufrieva, E.A. Anufriev, I.A. Korsakova, A.I. Shcherbakova, Worldview Formation of the Teacher-musician Personality in the Higher Education System, 99104 (2015), doi:10.5539/ass.v11n6p99

19. N.I. Anufrieva, E.A. Anufriev, et al, Personal Aesthetic Values Development as the Basis for a Modern Musician's Spiritual Formation, 569-574 (2015), Doi:10.5901/mjss.2015.v6n5s1p569

20. I.S. Kobozeva, M.P. Mironova, N.I. Chinyakova, Communicative Competency as Teacher's Integrative Ability for Musical Communication, 37-43 (2015), doi:10.5539/ass.v11n8p37

21. P.S.Volkova, V.I.Shakhovskiy, Spirituality in the Aspect of Art, 187-198 (2020), DOI: 10.33779/2587-6341.2020.4.187-198

22. I.V. Alekseeva, The Musical Text of Western European Baroque Instrumental Music in an Analytical Reevaluation by the Student-Performer of Institutions of Higher Education, 177-193 (2020), DOI: 10.33779/2587-6341.2020.1.177-193

23. N.I. Anufrieva, E.A. Anufriev, I.A.Korsakova, A.I.Shcherbakova, Worldview Formation of the Teacher-musician Personality in the Higher Education System, 99104 (2015), doi:10.5539/ass.v11n6p99 